\title{
Papers
}

\section{Cross sectional study of young people's awareness of and involvement with tobacco marketing}

Lynn MacFadyen, Gerard Hastings, Anne Marie MacKintosh

\begin{abstract}
Objectives To examine young people's awareness of and involvement with tobacco marketing and to determine the association, if any, between this and their smoking behaviour.

Design Cross sectional, quantitative survey, part interview and part self completion, administered in respondents' homes.

Setting North east England.

Participants Stratified random sample of 629 young people aged 15 and 16 years who had "opted in" to research through a postal consent procedure.

Results There was a high level of awareness of and involvement in tobacco marketing among the 15-16 year olds sampled in the study: around 95\% were aware of advertising and all were aware of some method of point of sale marketing. Awareness of and involvement with tobacco marketing were both significantly associated with being a smoker: for example, $30 \%(55 / 185)$ of smokers had received free gifts through coupons in cigarette packs, compared with $11 \%(21 / 199)$ of non-smokers $(\mathrm{P}<0.001)$. When other factors known to be linked with teenage smoking were held constant, awareness of coupon schemes, brand stretching, and tobacco marketing in general were all independently associated with current smoking status.

Conclusions Teenagers are aware of, and are participating in, many forms of tobacco marketing, and both awareness and participation are associated with current smoking status. This suggests that the current voluntary regulations designed to protect young people from smoking are not working, and that statutory regulations are required.
\end{abstract}

\section{Introduction}

The role of mass media advertising in encouraging smoking is now well established. Econometric studies, which model the effects of advertising expenditure on aggregate consumption, generally show that prevalence increases as the amount of advertising increases and reduces when advertising is banned. ${ }^{1}$ Consumer studies show that young people who smoke are more likely to appreciate and to be aware of tobacco advertising, ${ }^{2-12}$ sponsorship, ${ }^{13-15}$ and merchandising. ${ }^{16-19}$ Furthermore, cohort studies have shown that awareness and involvement with these forms of marketing predicts future smoking behaviour among young people. ${ }^{20}$

However, less is known about young people's experiences of other marketing devices, such as point of sale promotion, coupon schemes, brand stretching (the attachment of tobacco brands to non-tobacco products), or the internet. This study presents data from a cross sectional study of young people's experiences with the full range of such devices. While it cannot prove causal effects, it does show the scope and reach of tobacco marketing and provides support for tight and comprehensive regulation.

This is particularly relevant at present, as the detailed provisions of the UK government's primary legislation to ban tobacco advertising and promotion are currently being reviewed. ${ }^{21}$

\section{Methods}

The research examined young people's awareness of and involvement with a broad range of tobacco marketing activities. In line with previous studies on tobacco advertising, sponsorship, and merchandising, we expected that young people would be aware of and involved in other forms of tobacco marketing, and that this awareness and involvement would be positively associated with smoking status.

\section{Setting and data collection}

A random sample of 15 year olds, stratified by sex and postcode sector, was drawn from the patient registration database of a health authority in the north of England. Ethics committee approval was granted but required that names and addresses be passed to the researchers only after potential respondents had consented. Initially, therefore, a sample of 2400 was invited to participate in the research, which it was hoped would yield at least 280 smokers. Via their parents, all were sent an information sheet, questionnaire (to establish smoking status), consent form to be countersigned by a guardian, and a freepost return envelope. Two reminders were sent.

A total of 1062 young people consented, a response rate of $48 \%$ after redundant addresses were discounted. Other studies have shown that around one in five 15 year olds smoke, ${ }^{22}$ and in our sample 214 $(20 \%)$ were regular smokers; $825(78 \%)$ were not regular smokers, and $23(2 \%)$ did not state their smoking status. The consent process provided a more than
Centre for Tobacco
Control Research,
University of
Strathclyde,
Glasgow G4 0RQ
Lynn MacFadyen
research officer
Gerard Hastings
director
Anne Marie
MacKintosh
senior researcher
Correspondence to:
L MacFadyen
l.macfadyen@csm.
market.strath.ac.uk

BMJ 2001;322:513-7 
Table 1 Profile of sample of young people consenting to survey of awareness of and involvement in tobacco marketing. Values are numbers (percentages)

\begin{tabular}{|c|c|c|c|}
\hline Characteristic & Total $(n=629)$ & Boys $(n=253)$ & Girls $(n=376)$ \\
\hline \multicolumn{4}{|c|}{ Age at survey (years) } \\
\hline 14 & $1(<1 \%)$ & $0(0)$ & $1(<1 \%)$ \\
\hline 15 & 407 (65) & $173(68)$ & $234(62)$ \\
\hline 16 & $220(35)$ & $80(32)$ & $140(37)$ \\
\hline 17 & $1(<1 \%)$ & $0(0)$ & $1(<1 \%)$ \\
\hline \multicolumn{4}{|c|}{ Socioeconomic group } \\
\hline$A, B, C 1$ & $265(42)$ & $107(42)$ & $158(42)$ \\
\hline $\mathrm{C} 2, \mathrm{D}, \mathrm{E}$ & $364(58)$ & $146(58)$ & $218(58)$ \\
\hline \multicolumn{4}{|l|}{ Smoking status* } \\
\hline Non-smoker & $201(32)$ & $89(35)$ & $112(30)$ \\
\hline Tried smoking & $234(37)$ & $88(35)$ & $146(39)$ \\
\hline Current smoker & $185(29)$ & $70(28)$ & $115(31)$ \\
\hline Not stated & $9(1)$ & $6(2)$ & $3(1)$ \\
\hline \multicolumn{4}{|c|}{$\begin{array}{l}\text { *Non-smokers="never tried smoking, not even a puff"; tried="only ever smoked } \\
\text { once" or "used to smoke sometimes but never smoke now"; current="usually } \\
\text { smoke more than } 6 \text { cigarettes per week"or "usually smoke between } 1 \text { and } 6 \\
\text { cigarettes per week"or "sometimes smoke cigarettes now but not as many as } \\
1 \text { a week." }\end{array}$} \\
\hline
\end{tabular}

adequate sample of young people who were not regular smokers so, to minimise costs, we used random numbers to reduce this portion of the sample by 373 .

Ultimately 686 names and addresses were allocated to professional interviewers, who were briefed and instructed to make at least four attempts to contact and interview respondents. Interviewers were given no information concerning the smoking status of sample members. Parental permission was again obtained before the interview. Each respondent received a $£ 5$ gift voucher.

In all, 629 interviews were successfully completed. The time lapse between the initial sample selection and administering the survey meant that a third of respondents had reached age 16 . Two respondents (ages 14 and 17) were excluded from the later analysis. Young women were overrepresented in the sample (table 1).

Marketing techniques used to promote smoking in Britain

- Advertising: Billboards and press advertising

- Sponsorship: Sports-Formula 1, snooker, golf, rugby; arts-Fringe

Comedy Festival

- Point of sale: Promotional material in shops-branded gantry, clocks, signage, staff clothing

- Coupon schemes: Coupons included in packs of cigarettes that can be collected and exchanged for free gifts

- Merchandising: Production of low cost items (pens, lighters, or T shirts); competitions; other free gifts, including free cigarettes

- Special price offers: Short term offers of lower price advertised in-store, on pack flashes, or in packs

- Promotional mail: Any communication to customers including offers of cheaper cigarettes, information about new brands, new coupon schemes or others

- Brand stretching: Production of non-tobacco products with tobacco branding-Marlboro Classics clothes, Camel boots

- Pack design: Carefully designed to communicate brand image and to add value

- Internet sites: Websites promoting tobacco companies, cigarette brands, or smoking

- Product placement: Paid-for placement of cigarette brands by celebrities or characters in films or television
Extensive exploratory research and qualitative piloting informed the development and refinement of a two part questionnaire. The first part was suitable for a face to face interview; the second sought information on smoking status and was completed by the respondent. Show cards and coded answering procedures were used to enable the young people to respond freely even if parents were present during the interview, as happened in $44 \%$ of cases. Analysis showed that parents' presence did not influence response.

\section{Measures}

The questionnaire examined awareness of and involvement with different types of tobacco marketing (box); smoking status; and other variables known to be related to adolescent smoking (including intentions for future smoking and education; smoking by peers, siblings, and parents; gender; and social class).

\section{Statistical analysis}

We used bivariate analysis, including the $\chi^{2}$ test for trend and Kruskal-Wallis tests, to examine variations, by smoking status, in awareness of and involvement with tobacco marketing. Two logistic regression models were constructed to examine whether or not any association existed between awareness of tobacco marketing and smoking status, independently of other variables known to influence smoking. The first model examined marketing techniques separately; the second assessed their cumulative impact.

\section{Results}

Awareness of tobacco marketing communications Young people are very aware of tobacco marketing. Table 2 shows "prompted" awareness of different marketing techniques-that is, respondents were asked whether they had come across specific, named types of marketing, such as advertisements in magazines or newspapers or special price offers for cigarettes.

Nearly all had seen cigarette advertising on billboards, and over half had come across it in the press. All had seen some form of advertising at point of sale, and around half were aware of coupon schemes and special price offers for cigarettes.

Other forms of promotion were less familiar. Around a fifth of the sample had come across brand stretching (clothing or other items with cigarette logos on), new pack designs or sizes, free gifts offered on packets, competitions, and famous people smoking in films and on television. There was also awareness, at a lower level, of free gifts from the shopkeeper, promotional mail from cigarette companies, internet sites, and the distribution of free cigarettes.

Young smokers were more aware of virtually all forms of tobacco marketing than were non-smokers or those who had tried smoking (table 2). This trend was particularly noticeable for free gifts, special price offers, promotional mail, and pack design.

\section{Involvement with tobacco marketing}

Involvement with tobacco marketing was broadly similar for both male and female respondents (table 3). Many had actively participated in tobacco marketingfor example, by using coupon schemes or receiving 
Table 2 Number (percentage) of 15 and 16 year olds aware of tobacco marketing

\begin{tabular}{|c|c|c|c|c|}
\hline & \multicolumn{3}{|c|}{ Smoking status } & \multirow[b]{2}{*}{$\begin{array}{c}\text { P value } \\
\left(\chi^{2} \text { test for trend }\right)\end{array}$} \\
\hline & $\begin{array}{c}\text { Non-smoker } \\
(n=199)\end{array}$ & $\begin{array}{l}\text { Tried smoking } \\
(\mathrm{n}=234)\end{array}$ & $\begin{array}{l}\text { Current smoker } \\
(\mathrm{n}=185)\end{array}$ & \\
\hline Advertising & $188(94)$ & $220(94)$ & $176(95)$ & 0.783 \\
\hline \multicolumn{5}{|l|}{ Any advertising } \\
\hline Advertisements for cigarettes in newspapers or magazines & $104(52)$ & $136(58)$ & $116(63)$ & 0.055 \\
\hline Advertisements for cigarettes on large posters or billboards on the street & $180(90)$ & $207(88)$ & $172(93)$ & 0.287 \\
\hline \multicolumn{5}{|l|}{ Point of sale marketing } \\
\hline Any point of sale marketing & $199(100)$ & $234(100)$ & $185(100)$ & - \\
\hline Cigarette signs or posters on clocks inside shops & $76(38)$ & $91(39)$ & $93(50)$ & 0.018 \\
\hline Free gifts when people save coupons or tokens from inside cigarette packs & $105(53)$ & $130(56)$ & $138(75)$ & $<0.001$ \\
\hline Free gifts when people save parts of the cigarette packs & $38(19)$ & $49(21)$ & $74(40)$ & $<0.001$ \\
\hline $\begin{array}{l}\text { Free gifts showing cigarette brand logos given out at events such as } \\
\text { concerts, festivals, or sports events }\end{array}$ & $26(13)$ & $30(13)$ & $32(17)$ & 0.410 \\
\hline Free gifts from the shopkeeper when people buy cigarettes & $15(8)$ & $17(7)$ & $24(13)$ & 0.114 \\
\hline Special price offers for cigarettes & $93(47)$ & $121(52)$ & $112(61)$ & 0.005 \\
\hline Clothing or items with cigarette brand names or logos on them & $41(21)$ & $41(18)$ & $56(30)$ & 0.035 \\
\hline Promotional mail from cigarette companies being delivered to people's homes & $15(7)$ & $36(15)$ & $35(19)$ & 0.001 \\
\hline Competitions or prize draws linked to cigarettes & $28(14)$ & $36(15)$ & $36(19)$ & 0.300 \\
\hline New pack design or size & $34(17)$ & $26(11)$ & $54(29)$ & 0.017 \\
\hline Famous people in films or on television with a particular brand of cigarettes & $31(16)$ & $48(21)$ & $44(24)$ & 0.132 \\
\hline Internet sites for cigarettes or smoking & $8(4)$ & $14(6)$ & $7(4)$ & 0.358 \\
\hline Free trial cigarettes being given out or offers to send away for free cigarettes & $8(4)$ & $18(8)$ & $21(11)$ & 0.013 \\
\hline Average number of marketing techniques aware of & 6.4 & 6.7 & 8.1 & $<0.001^{*}$ \\
\hline
\end{tabular}

*One way analysis of variance: $F=15.257, d f=2, P<0.001$.

direct mail. Over half of current smokers had participated in tobacco marketing of one form or another, compared with around a quarter of nonsmokers and those who had tried smoking. Almost a third of smokers had received free gifts through coupon schemes, over a quarter had received special price offers for cigarettes and around a tenth had received free gifts at events or had been exposed to promotional mail.

\section{Association between awareness of tobacco marketing and smoking status}

Table 4 shows the association between awareness of each tobacco marketing technique and current smoking status when other variables that are known to be linked with teenage smoking were controlled for. Awareness of coupon schemes and brand stretching were both associated with the greater probability of being a current smoker, as was having friends, siblings, or a mother who smoked. In this model, having friends who smoke was most strongly associated with being a current smoker.

The number of tobacco marketing techniques of which young people were aware was positively related to current smoking status (table 5). Having friends, siblings, or a mother who smoked was associated with a greater probability of being a current smoker.

\section{Discussion}

Young people aged 15-16 are aware of, and participating in, many forms of tobacco marketing, and this phenomenon is consistently associated with being a smoker. When other factors that are known to be linked with teenage smoking are held constant, awareness of coupon schemes and brand stretching, and tobacco marketing in general, are all independently associated with current smoking.

In some instances this may be explained by the greater exposure that young smokers are likely to have

Table 3 Number (percentage) of 15 and 16 year olds involved with tobacco marketing

\begin{tabular}{|c|c|c|c|c|}
\hline & \multicolumn{3}{|c|}{ Smoking status } & \multirow[b]{2}{*}{$\begin{array}{c}\text { P value } \\
\left(\chi^{2} \text { test for trend }\right)\end{array}$} \\
\hline & $\begin{array}{c}\text { Non-smoker } \\
(\mathrm{n}=199)\end{array}$ & $\begin{array}{l}\text { Tried smoking } \\
(\mathrm{n}=234)\end{array}$ & $\begin{array}{l}\text { Current smoker } \\
(\mathrm{n}=185)\end{array}$ & \\
\hline $\begin{array}{l}\text { Received free gifts as a result of self or someone else collecting coupons or } \\
\text { tokens from inside cigarette packs }\end{array}$ & $21(11)$ & $38(16)$ & $55(30)$ & $<0.001$ \\
\hline $\begin{array}{l}\text { Received free gifts as a result of self or someone else saving parts of } \\
\text { cigarette packs (eg pack fronts) }\end{array}$ & $11(6)$ & $14(6)$ & $31(17)$ & $<0.001$ \\
\hline Received special price offers for cigarettes & $7(4)$ & $12(5)$ & $51(28)$ & $<0.001$ \\
\hline Received promotional mail from cigarette companies & $6(3)$ & $11(5)$ & $16(9)$ & 0.015 \\
\hline $\begin{array}{l}\text { Received free gifts showing cigarette brand logos given out at events such as } \\
\text { concerts, festivals, or sports events }\end{array}$ & $6(3)$ & $10(4)$ & $16(9)$ & 0.014 \\
\hline Owned clothing or other items with a cigarette brand name or logo & $3(2)$ & $9(4)$ & $15(8)$ & 0.002 \\
\hline Looked at an internet site for cigarettes or smoking & $3(2)$ & $5(2)$ & $5(3)$ & 0.415 \\
\hline Received free gifts from the shopkeeper when buying cigarettes & $1(<1)$ & $5(2)$ & $5(3)$ & 0.101 \\
\hline Entered a competition that was linked to cigarettes & $2(1)$ & $4(2)$ & $10(5)$ & 0.007 \\
\hline Received free trial cigarettes & $0(0)$ & $2(1)$ & $10(5)$ & $<0.001$ \\
\hline Done any of these & $45(23)$ & $65(28)$ & $97(52)$ & $<0.001$ \\
\hline
\end{tabular}


Table 4 Logistic regression analysis of variables associated with odds of being a current smoker in relation to types of tobacco marketing

\begin{tabular}{|c|c|c|c|}
\hline Variable (reference category) & No & Odds ratio $(95 \% \mathrm{Cl})$ & $P$ value \\
\hline \multicolumn{4}{|l|}{ Awareness of coupon schemes: } \\
\hline Yes (no) & 395 & 1.90 (1.18 to 3.05$)$ & 0.008 \\
\hline \multicolumn{4}{|c|}{ Awareness of clothing or other items with cigarette logos on them: } \\
\hline Yes (no) & 139 & 1.78 (1.11 to 2.88$)$ & 0.018 \\
\hline \multicolumn{4}{|l|}{ Number of friends who smoke: } \\
\hline All of them (none of them) & 43 & 36.50 (9.33 to 142.81$)$ & $<0.0001$ \\
\hline Most of them (none of them) & 205 & 18.41 (5.49 to 61.78$)$ & $<0.0001$ \\
\hline About half of them (none of them) & 146 & 7.52 (2.18 to 25.97$)$ & 0.001 \\
\hline A few of them (none of them) & 126 & 2.08 (0.55 to 7.86$)$ & 0.282 \\
\hline Not sure (none of them) & 19 & 8.19 (1.54 to 43.42) & 0.013 \\
\hline \multicolumn{4}{|l|}{ Any siblings who smoke: } \\
\hline Yes (no) & 185 & 2.78 (1.80 to 4.30$)$ & $<0.0001$ \\
\hline Not sure (no) & 47 & 2.71 (1.14 to 6.46$)$ & 0.025 \\
\hline \multicolumn{4}{|l|}{ Mother smokes: } \\
\hline Yes (no) & 231 & 1.91 (1.26 to 2.92$)$ & 0.003 \\
\hline No mother (no) & 9 & 3.48 (0.81 to 15.01$)$ & 0.095 \\
\hline Not sure (no) & 20 & $0.19(0.03$ to 1.00$)$ & 0.050 \\
\hline Constant & & 0.013 & $<0.0001$ \\
\hline
\end{tabular}

Variables were included in the analyses in a forward stepwise procedure. A probability of 0.05 was used for a variable to enter the equation and a probability of 0.10 to be removed.

The dependent current smoker (1) was compared against non-smokers and tried smokers (0).

The independents included all marketing variables (advertising, point of sale, coupon schemes, sponsorship, promotions, special price offers, promotional mail, brand stretching, famous people in TV and films, new pack design or size, and internet sites) and all controls (including gender, age, friends' smoking, sibling's smoking, mother's smoking, father's smoking, socioeconomic group, marital status of parents, future education intentions, and parental presence during interview).

to certain forms of tobacco marketing (package design or price promotions, for example), but not in others (brand stretching and shop advertising). In any case, it is likely that young people, and especially young smokers, are getting some kind of benefit or reassurance from these different forms of tobacco marketing. Previous researchers have drawn a link between this type of reward and the reinforcement of smoking. ${ }^{20}$

This confirms the need for statutory controls on tobacco marketing; the current voluntary regulations designed to protect young people are clearly not working. It also suggests that the Tobacco Advertising and Promotion Bill should be comprehensive: it should

Table 5 Logistic regression analysis of variables associated with odds of being a current smoker in relation to amount of tobacco marketing

\begin{tabular}{|c|c|c|c|}
\hline Variable (reference category) & No & Odds ratio $(95 \% \mathrm{Cl})$ & $P$ value \\
\hline Total number of tobacco marketing techniques of which aware & & $1.13(1.06$ to 1.20$)$ & $<0.0001$ \\
\hline \multicolumn{4}{|l|}{ Number of friends who smoke: } \\
\hline All of them (none of them) & 43 & 29.38 (7.56 to 114.12$)$ & $<0.0001$ \\
\hline Most of them (none of them) & 205 & 16.05 (4.82 to 53.50$)$ & $<0.0001$ \\
\hline About half of them (none of them) & 146 & $6.72(1.95$ to 23.07$)$ & 0.002 \\
\hline A few of them (none of them) & 126 & $1.92(0.51$ to 7.21$)$ & 0.336 \\
\hline Not sure (none of them) & 19 & 7.21 (1.37 to 37.92$)$ & 0.020 \\
\hline \multicolumn{4}{|l|}{ Any siblings who smoke: } \\
\hline Yes (no) & 185 & 3.01 (1.94 to 4.66$)$ & $<0.0001$ \\
\hline Not sure (no) & 47 & 2.93 (1.26 to 6.82$)$ & 0.013 \\
\hline \multicolumn{4}{|l|}{ Mother smokes: } \\
\hline Yes (no) & 231 & 1.97 (1.29 to 2.98$)$ & 0.002 \\
\hline No mother (no) & 9 & 3.26 (0.77 to 13.82$)$ & 0.109 \\
\hline Not sure (no) & 20 & 0.21 (0.04 to 1.13$)$ & 0.069 \\
\hline Constant & & 0.01 & 0.010 \\
\hline
\end{tabular}

Variables were included in the analyses in a forward stepwise procedure. A probability of 0.05 was used for a variable to enter the equation and a probability of 0.10 to be removed.

The dependent current smoker (1) was compared against non-smokers and tried smokers (0).

The analysis included the following controls: gender, age, friends' smoking, sibling's smoking, mother's

smoking, father's smoking, socioeconomic group, marital status of parents, future education intentions, and

parental presence during interview.
What is already known about this topic

Tobacco advertising, sponsorship, and merchandising encourage teenage smoking

The effect of other forms of tobacco marketing, such as brand stretching or coupon schemes, is unknown

\section{What this study adds}

15-16 year olds are aware of and participate in these other forms of tobacco marketing, and this phenomenon is consistently associated with being a smoker

When other factors known to be linked with teenage smoking are held constant, awareness of coupon schemes, brand stretching, and tobacco marketing in general are all independently associated with current smoking

This suggests that young people, and especially young smokers, are getting some kind of benefit or reward from tobacco marketing

outlaw not just the specific practices of couponing and brand stretching, but all forms of tobacco marketing.

Finally, flexibility is also likely to be important; there is a need to combat the marketing innovations that will undoubtedly emerge as the bill takes effect. The establishment of a Tobacco Regulatory Authority, as proposed by last year's Select Committee report, ${ }^{23}$ is the obvious way to achieve this.

We thank the respondents and acknowledge the support of the fieldforce team and Newcastle and North Tyneside Health Authority.

Contributors: The research was conceived and supervised by $\mathrm{GH}$, who also provided direction for the paper. LM conducted the initial exploratory research, questionnaire design and piloting, data analysis, and report writing. AMM provided guidance and support for the questionnaire design and data analysis. Susan Anderson managed the fieldforce team and the data collection process. Dr Ray Lowry assisted with the sample generation and ethics approval. GH will act as guarantor.

Funding: This study was largely funded by the Cancer Research Campaign, with additional support from the Department of Health.

Competing interests: None declared.

1 Economics and Operational Research Division, Department of Health (UK). Effect of tobacco advertising on tobacco sponsorship: a discussion document reviewing the evidence. London: Department of Health, 1992. (Smee reviewing

2 Aitken PP, Leather DS, O'Hagan F, Squair SI. Children's awareness of cigarette advertisements and brand imagery. Br J Addict 1987;82:615-22.

3 Di Franza JR, Richards JW, Paulman PM, Wolf-Gillespie W, Fletcher C, Jaffe RD, et al. RJR Nabisco's cartoon camel promotes Camel cigarettes to children. JAMA 1991;266:3149-53.

4 Potts H, Gillies P, Herbert M. Adolescent smoking and opinion of cigarette advertisements. Health Educ Res 1986;1:195-201.

5 Aitken PP, Eadie DR. Reinforcing effects of cigarette advertising on underage smoking. BrJ Addict 1990;85:399-412.

6 Pierce JP, Gilpin E, Burns DM, Whalen E, Rosbrook B, Shopland D, et al. Does tobacco advertising target young people to start smoking? JAMA 1991;266:3145-8.

7 Covell K, Dion Kl, Dion KK. Gender differences in evaluations of tobacco and alcohol advertisements. Can J Behav Med 1994;26:404-20.

8 Pechmann C, Ratneshwar S. The effects of anti-smoking and cigarette advertising on young adolescents' perceptions of peers who smoke. $J$ Consumer Res 1994;21:236-51.

9 Arnett JJ, Terhanian G. Adolescents' responses to cigarette advertisements: links between exposure, liking, and the appeal of smoking. Tob Control 1998;7:129-33.

10 Unger JB, Anderson C, Rohrbach LA. Recognition and liking of tobacco and alcohol advertisements among adolescents: relationships with susceptibility to substance use. Prev Med 1995;24:461-6. 
11 Evans N, Farkas A, Gilpin E, Berry C, Pierce JP. Influence of tobacco marketing and exposure to smokers on adolescent susceptibility to smoking J Natl Cancer Inst 1995;87:1538-45.

12 Feighery E, Borzekowski DL, Schoder C, Flora J. Seeing, wanting, owning: the relationship between receptivity to tobacco marketing and smoking susceptibility in young people. Tob Control 1998;7:123-8.

13 Ledwith F. Does sports sponsorship act as advertising to children? Health Educ J 1984;43:85-8.

14 Piepe AP, Charlton P, Morey J, Yerrell P, Ledwith F. Does sponsored sport lead to smoking among children? Health Educ J 1986;45:145-8.

15 Charlton A, While D, Kelly S. Boys' smoking and cigarette-brandsponsored motor racing. Lancet 1997;350:1474.

16 Altman DG, Levine DW, Coeytaux R, Slade J, Jaffe R. Tobacco promotion and susceptibility to tobacco use among adolescents aged 12 through 17 and susceptibility to tobacco use among adolescents aged 12 through 17 years in a na

17 Gilpin EA, Pierce JP, Rosbrook B. Are adolescents receptive to current sales promotion practices of the tobacco industry? Prev Med 1997;26:14-21.
18 Pierce JP, Choi WS, Gilpin EA, Farkas AJ, Berry CC. Tobacco industry promotion of cigarettes and adolescent smoking. JAMA 1998;279:511-5. 19 Redmond WH. Effect of sales promotion on smoking in US ninth graders. Prev Med 1999;28:243-50.

20 Aitken PP, Eadie DR, Hastings GB, Haywood AJ. Predisposing effects of cigarette advertising on children's intentions to smoke when older. $\mathrm{BrJ}$ Addiction 1991;86:383-90.

21 UK Parliament. Public bills before parliament. Tobacco Advertising and Promotion Bill. www.parliament.the-stationery-office.co.uk/pa/pabills.htm (accessed 19 Feb 2000).

22 Higgins V. Young teenagers and smoking in 1998: a report of the key finding from the teenage smoking attitudes survey carried out in England in 1998. London: ONS Social Survey Division, 1998.

23 House of Commons Health Committee. Second report. The tobacco industr and the health risks of smoking. Vol 1. London: Stationery Office, 2000.

(Accepted 16 February 2001)

\title{
Adverse events in British hospitals: preliminary retrospective record review
}

\author{
Charles Vincent, Graham Neale, Maria Woloshynowych
}

\begin{abstract}
Objectives To examine the feasibility of detecting adverse events through record review in British hospitals and to make preliminary estimates of the incidence and costs of adverse events.

Design Retrospective review of 1014 medical and nursing records.

Setting Two acute hospitals in Greater London area. Main outcome measure Number of adverse events. Results 110 (10.8\%) patients experienced an adverse event, with an overall rate of adverse events of $11.7 \%$ when multiple adverse events were included. About half of these events were judged preventable with ordinary standards of care. A third of adverse events led to moderate or greater disability or death. Conclusions These results suggest that adverse events are a serious source of harm to patients and a large drain on NHS resources. Some are major events; others are frequent, minor events that go unnoticed in routine clinical care but together have massive economic consequences.
\end{abstract}

\section{Introduction}

Retrospective studies of hospital case records in the United States and Australia have shown a substantial rate of adverse events, defined as unintended injuries caused by medical management rather than the disease process. The Harvard medical practice study found that $3.7 \%$ of hospital admissions led to adverse events. ${ }^{12}$ In $70 \%$ of these patients the adverse event led to slight or short lived disabilities, but in $7 \%$ the disabilities were permanent and in $14 \%$ they contributed to death. Similar rates were found in a study from Colorado and Utah. ${ }^{34}$ The quality in Australian healthcare study identified adverse events in $16.6 \%$ of admissions, half of which were considered preventable. ${ }^{5}$ This study included a wider range of adverse events of minor or moderate severity. Other methodological differences also exaggerate the difference between the United States and Australian figures. ${ }^{46}$ The Australian study estimated that adverse events accounted for $8 \%$ of hospital bed days and cost the Australian healthcare system $\$ 4.7 \mathrm{bn}$ a year. Adverse events also result in huge personal cost to the affected individuals, both patients and staff. ${ }^{7}$

The epidemiology of adverse events has not been studied in Britain. We report preliminary findings from a pilot study that examined the feasibility of applying United States and Australian methods and the potential value of a parallel study in the United Kingdom.

\section{Methods}

\section{Design and procedure}

The study was carried out at two acute hospitals in the London area. We reviewed 500 randomly drawn records from site 1 between July and September 1999 and 514 records from site 2 between December 1999 and February 2000. In both sites the index admissions studied occurred in two months in 1998, about a year before the review periods. We reviewed 273 (26.9\%) records from general medicine (including geriatrics), $290(28.6 \%)$ from general surgery, $277(27.3 \%)$ from orthopaedic surgery, and 174 (17.2\%) from obstetrics. Admissions to the four specialties studied in 1998-9 were 19397 in site 1 and 18335 in site 2. The proportions of admissions studied were $2.6 \%$ and $2.8 \%$ respectively.

\section{Review process}

The review team consisted of an experienced nurse who worked as project manager with four part time research nurses. A consultant physician acted as lead medical assessor, working with five part time surgical and obstetric colleagues, each of whom had been qualified for a minimum of 10 years. Each reviewer screened sets of notes under supervision until they were judged to be fully conversant with the review process.

The nurse reviewers used 18 predefined screening criteria to assess the case records. Records that

\section{Editorial by Alberti Letters p 548 \\ Reviews pp 562, 563 \\ Clinical Risk Unit, Department of Psychology, University College London, London WC1E 6BT \\ Charles Vincent professor of psychology Graham Neale consultant physician Maria \\ Woloshynowych research fellow \\ Correspondence to: C Vincent \\ c.vincent@ucl.ac.uk}

BMJ 2001;322:517-9

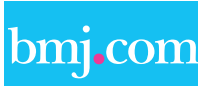

The criteria for adverse events and tables of results is available on the BMJ's website 